\title{
Fear of childbirth in pregnant women in the United States
}

\author{
Runnals JJ' and Vrana $\mathrm{SR}^{2 *}$ \\ ${ }^{1}$ Department of Veterans Affairs Medical Center Durham, North Carolina, USA \\ ${ }^{2}$ Department of Psychology, Virginia Commonwealth University Richmond, Virginia, USA
}

\begin{abstract}
Objective: The purpose of this investigation was to assess the incidence of serious childbearing fear in a sample of American women, and to explore associations between women's experiences and fear of childbirth.

Methods: Ninety women 25 weeks of gestation and later who participated in a prospective longitudinal study were administered questionnaires during pregnancy that included background factors (marital status, education, birth history), fear of childbirth, and current levels of depression and posttraumatic stress disorder symptomology.

Results: The incidence of serious fear of childbirth (7.7\%) was slightly lower than but consistent with studies of Northern European women. When considered separately, $11.6 \%$ of women in the care of an obstetrician and $4 \%$ of women in the care of a midwife exhibited serious levels of fear. Greater fear of childbirth was seen in women experiencing sexual assault in both childhood and adulthood but not in women endorsing childhood sexual assault alone. Fear was higher among women with a current diagnosis of depression or co-morbid depression and Posttraumatic Stress Disorder.
\end{abstract}

Conclusion: These results underscore the importance of identifying and treating depression in pregnant women.

\section{Introduction}

Studies of Northern European women indicate that serious levels of childbearing fear occur in $7.3 \%$ to $15.6 \%$ of pregnant women [17]. Excessive childbearing fear is a concern given its relationship with increased healthcare utilization $[8,9]$, complicated birth $[10,11]$, and increased risk for instrument-assisted or operative deliveries $[1,5,12]$. Fear of childbirth is a topic that has received little objective investigation in American women despite its influence on maternal request cesarean sections [12-15], which have increased in the U.S., the controversy surrounding these requests [16-17], and concern about the lack of information suggesting how providers attend to serious childbirth fear.

More fearful women have excessive concerns regarding child malformation, physical damage to the fetus, painful injections, injury to the fetus or themselves during delivery, and fear of pain or of becoming hysterical during delivery [18-20]. Understanding what concerns women with serious childbirth fear does not necessarily illuminate why some women are more afraid than others. Explanations for severe fear have included exposure to traumatic stories of childbirth or actual experience of traumatic birth [21], fear of the unknown among first-time mothers [22-24], and history of sexual abuse [1]. It is unknown whether similar factors are associated with fear in American women and what role the presence of trauma and depressionrelated symptomology may play in fear of childbirth.

Given the paucity of information regarding childbearing fear in women from the U.S. this study was undertaken to investigate childbearing fear in American women. It was expected that women with childhood sexual assault would be more fearful of birth and it was hypothesized that women with a history of miscarriage, difficult birth, and current trauma or depression diagnosis would have higher levels of fear.

\section{Materials and Methods \\ Participants and procedures}

After obtaining approval from the Virginia Commonwealth University Institutional Review Board, data were collected in a number of sites in the mid-Atlantic by approaching women attending prenatal appointments in participating clinics, and by placing advertisements in clinics and local businesses. Women were eligible to participate if they were 18 or older, past their 24th week of gestation and provided informed consent. Women who met criteria were given a packet of selfadministered questionnaires and a pre-addressed, stamped envelope to return measures.

\section{Measures}

The packet included questions regarding background information (e.g., age, race, income and employment status, marital status, number of children, and obstetrical variables such as current week of gestation, type of prenatal care provider, past birth experience including type of prior delivery, history of miscarriage, history of stillbirth, whether they had asked their provider for surgical delivery based on childbearing fear, and a rating of their preference for c-section over vaginal delivery) as well as the following measures: 1) The Wijma Delivery Expectancy Questionnaire ([25]; WDEQ), a 33-item measure of childbearing fear with scores ranging from $0-165$ and the consensus choice in the field

Correspondence to: Scott R Vrana, PhD, Department of Psychology Virginia Commonwealth University Richmond, Virginia, 23284-2018, USA, Phone: 01804-828-1242, E-mail: srvrana@vcu.edu

\section{Key words: depression, fear of childbirth, United States}

Received: April 13, 2018; Accepted: April 19, 2018; Published: April 28, 2018 
for measuring this construct [26]. Researchers suggest a cut-off score of $\geq 85$ as indicating serious fear of childbirth [5-7]. 2) The Edinburg Postnatal Depression Scale ([27]; EPDS), a ten-item screening of postnatal depression symptomology that has been validated for use during pregnancy [28]. Based upon prior work [27, 29, 30] a cut-off score of 12 was used to indicate likely diagnostic levels of depression. 3) The Posttraumatic Diagnostic Scale ([31]; PDS) a 57-item measure of recent Posttraumatic Stress Disorder (PTSD) symptomology and assessment of all DSM-IV criteria for PTSD. The PDS has been used in prior studies of pregnant and postpartum women [32,33] and was suggested as an appropriate self-report measure by a consortium of researchers of pre and postpartum trauma [34].

For this study, early sexual assault (ESA) refers to positive endorsement of the PDS item assessing sexual contact prior to age 18 with someone five or more years older. Repeated sexual assault (RSA) refers to women's endorsement of early sexual assault and sexual assault in adulthood. Womenwere considered to have a trauma diagnosis if they met criteria for PTSD or if they were subthreshold (i.e. endorsed criterion A1 and A2 for diagnosis of PTSD but did not fully meet $\mathrm{B}, \mathrm{C}$, or $\mathrm{D}$ criteria or alternatively did not meet criterion A2 but did endorse diagnostic levels of trauma symptomology). Prior difficult birth was assessed by endorsement of the following: "difficult or upsetting childbirth (for example, an emergency c-section or forceps delivery, stillborn child, extremely painful labor, or a lot of tearing during delivery)".

\section{Analyses}

The results are reported as mean and standard deviation and when appropriate as percentages with $90 \%$ confidence intervals. Group comparisons of continuous data were made with independent t-tests or Analysis of Variance (ANOVA) and categorical data with chi-square tests for independence. A significance level of $\mathrm{p}<.05$ was considered statistically relevant.

\section{Results}

\section{Sample description}

One-hundred and four women agreed to enroll in the study. Ninety women returned the pre-delivery packet of questionnaires, an $84 \%$ response rate, which is consistent with [5] or exceeds $[1,2,6]$ response rates in similar studies. Demographic characteristics of the 90 participants are shown in Table 1. The sample is not representative of all childbearing women in the U.S. as it consisted primarily of working and college-educated, married, Caucasian women. In addition, half of the participants were in the care of a midwife, which significantly exceeds the typical rate of $7 \%$ women in midwifery care in the United States. Seventeen women (18.8\%) reported sexual assault during childhood on the PDS; adult or childhood sexual assault was endorsed by $28 \%$ of participants. Both childhood and adult sexual assault were reported by $10 \%$ of women $(n=9)$. Four or $4.4 \%$ of participants were assigned a diagnosis of PTSD based on the PDS, which is lower than population estimates of 10-12\% [35-37]. An additional 14\% met criteria for subthreshold PTSD. Twenty-four percent of participants were assigned a diagnosis of depression based on exceeding the cut-off score of 12 on the EPDS.

\section{Incidence of childbearing fear}

Internal reliability of the WDEQ was high (Cronbach's $\alpha=.93$ ) and consistent with prior work $[1,5]$. Similar to prior studies, mean fear for the entire sample was $54.1(\mathrm{SD}=21.2)$. The incidence of serious fear
Table 1. Participant characteristics.

\begin{tabular}{|l|l|}
\hline Characteristic (n=90) & M (SD) or \% \\
\hline Age (in years) & $30.47(4.58)$ \\
\hline Education (in years) & $15.73(2.30)$ \\
\hline Income Level & $\$ 46,577(14,475)$ \\
\hline$\%$ African-American & $10 \%$ \\
\hline$\%$ married & $85.6 \%$ \\
\hline Employed F/PT & $62.2 \%$ \\
\hline History of Psychiatric Diagnosis & $63.3 \%$ \\
\hline Any Sexual Trauma & $27.8 \%$ \\
\hline Early Sexual Trauma & $10 \%$ \\
\hline OB Provider & $47.8 \%$ \\
\hline Midwife Provider & $52.2 \%$ \\
\hline Prior Birth Experience & $43.3 \%$ \\
\hline Endorsement of $\geq$ Criterion A Event & $71 \%$ \\
\hline PTSD Diagnostic Scale & $4.17(6.89)$ \\
\hline Depression Symptoms on EPDS & $8.01(4.96)$ \\
\hline Fear of L\&D on WDEQ & $54.12(21.20)$ \\
\hline
\end{tabular}

Note. EPDS=Edinburgh Postnatal Depression Scale; WDEQ-A=Wijma Delivery Expectancy Questionnaire.

of childbirth, defined as WDEQ $\geq 85$, was $7.7 \%$ (90\% CI [3.1\%, 12.3\%] ; $\mathrm{n}=7$ ), which is generally lower than rates for non-U.S. women. Of women in the care of an obstetrician $11.6 \%$ (90\% CI [5.6\%, 16.4\%]; $\mathrm{n}=5$ ) showed serious childbearing fear. This is more commensurate with rates of fear in non-U.S. women than the $4.0 \%$ (90\% CI [0.6\%, $7.4 \%] ; \mathrm{n}=2$ ) rate for women in care of a midwife. Fear among obstetrical patients was greater $(\mathrm{X}=61.9 \mathrm{SD}=21.0)$ than among midwifery patients $(X=47.0, S D=18.9), t(88)=3.54, p<.001$. Four percent of women $(n=4)$ indicated having already requested a c-section for fear; however only two of these women had fear levels on the WDEQ $\geq 85$, suggesting that the weight women give to certain aspects of fear, rather than only the absolute amount of fear, may play a role in some maternal requests for cesarean section for fear. Thus a WDEQ score of $\geq 85$ may not capture all women who would like to avoid vaginal delivery due to fearfulness. There was a moderate correlation between level of childbearing fear and increasing preference for surgical over vaginal delivery $(r=.31$, $\mathrm{N}=90, \mathrm{p}<.001)$.

\section{Factors associated with childbearing fear}

Table 2 shows the results from group comparisons of childbearing fear in women with and without prior birth experience (women with history of birth trauma were excluded from this comparison), history of miscarriage, prior difficult birth (women with no birth history were excluded from this comparison), and past sexual assault. Contrary to a prior finding [14] but consistent with more recent work [4, 38] women with and without history of miscarriage showed similar levels of childbearing fear. As expected, mean fear scores were higher in women with prior difficult birth and higher among women reporting early sexual assault; however, these differences did not reach statistical significance. For women who endorsed repeated sexual assault (RSA) their level of childbearing fear was significantly greater than women not reporting RSA. Thirty-three percent of women with repeated sexual assault were high in fear compared to $4.9 \%$ of women without history of repeated sexual assault, a relative risk increase of $73 \%$.The results partially support the hypothesis that women with PTSD would have greater levels of childbearing fear given posttraumatic symptoms such as hypervigilance for danger: Fear levels were moderately correlated with trauma $(\mathrm{r}=.32, \mathrm{p}<.01)$ and depression $(\mathrm{r}=.50, \mathrm{p}<.01)$ symptomology. As shown in Table 3 , in a one-way ANOVA using Tukey's HSD for post-hoc analyses, women with a trauma diagnosis 
Table 2. Independent t-tests Comparing Childbearing Fear on WDEQ Between Women with a History of Miscarriage, Prior Difficult Birth, and Sexual Assault.

\begin{tabular}{|c|c|c|c|c|c|c|c|}
\hline Variable & $n=$ yes & M (SD) & n=no & M (SD) & t-score & $\mathbf{p}$ & ES \\
\hline Prior Birth & 27 & $51.26(22.79)$ & 51 & $54.94(20.47)$ & $\mathrm{t}(76)=.727$ & .47 & .0070 \\
\hline Difficult Birth & 12 & $57.08(21.74)$ & 27 & $51.26(21.22)$ & $t(37)=-.747$ & .46 & .0148 \\
\hline ESA & 17 & $58.77(27.32)$ & 73 & $53.04(19.59)$ & $\mathrm{t}(88)=-.1 .00$ & .32 & .0112 \\
\hline RSA & 9 & $68.33(24.82)$ & 81 & $52.54(20.32)$ & $t(88)==2.16$ & .03 & .0504 \\
\hline Miscarriage & 23 & $54.52(24.19)$ & 67 & $53.98(20.27)$ & $\mathrm{t}(88)=-.104$ & .92 & .0001 \\
\hline
\end{tabular}

Note. $\mathrm{ESA}=$ early sexual assault; $\mathrm{RSA}=$ repeated sexual assault; $\mathrm{ES}=$ effect size.

Table 3. Childbearing Fear Among Women with Depression, Trauma Diagnosis, Both, or No Diagnosis.

\begin{tabular}{|c|c|c|c|}
\hline Group & n & M & SD \\
\hline No Diagnosis & 59 & $48.32^{*} \dagger$ & 20.06 \\
\hline Trauma Diagnosis Only & 8 & 53.88 & 16.13 \\
\hline Depression Only & 13 & $68.08^{*}$ & 19.23 \\
\hline $\begin{array}{c}\text { Trauma Diagnosis \& } \\
\text { Depression }\end{array}$ & 9 & $72.89 \dagger$ & 16.93 \\
\hline
\end{tabular}

Note. $*$ and $\dagger$ indicate significant differences between groups, $\mathrm{p} \leq .05$.

were higher in fear than women with no diagnosis; however, it was only among women with co-morbid depression and trauma diagnosis, or depression alone, that the difference in level of fear between those with and without diagnoses reached statistical significance. Of the seven women in this study with serious childbirth fear, five met criteria for a likely diagnosis of depression; $22.7 \%$ of women with depression were also seriously fearful of childbirth compared to $2.9 \%$ of women without depression, a relative risk increase of $82 \%$.

Given that women who experience sexual contact or assault during childhood and who subsequently experience sexual assault during adulthood are particularly susceptible to comorbid psychological disorders [39-43], a chi-square test was conducted looking at the association between repeated sexual assault and diagnostic status (no diagnosis, trauma only, depression only, or both). This test was marginally significant $[\chi 2(3, \mathrm{~N}=90)=6.32, \mathrm{p}=.09$, $\mathrm{phi}=.27]$. Both RSA (yes or no) and level of depressive symptomology were then entered into a regression analysis to determine whether current levels of depression would better account for the variance in childbearing fear than repeated sexual assault and whether RSA is a predictor of childbearing fear only at higher levels of depression. Repeated sexual assault was entered in step one and accounted for $5.3 \%$ of the variance in childbearing fear. Depression symptoms were entered in step two explaining an additional $22.7 \%$ of the variance in childbearing fear. The interaction of depression symptoms and repeat sexual assault was entered in step three and while the full model was significant, $\mathrm{F}(3,85)=11.26, \mathrm{p}<.01$, accounting for $28.4 \%$ of the variance in childbearing fear, the only significant predictor in the final step was depression. In this sample $78 \%$ of women with RSA and depression diagnosis $(n=7)$ were high in childbearing fear whereas no women with RSA who lacked depression diagnosis $(n=2)$ were high in fear. These results suggest that the relationship between repeated sexual assault and fear of childbirth is mediated by depression.

\section{Discussion}

The main goals of this study were to assess levels of serious childbirth fear and factors associated with fear in a sample of pregnant American women. Incidence of serious childbirth fear was 7.7\%. The incidence of fear was higher (11.6\%) when only considering women in the care of an obstetrician, though these women may have additional reasons for increased fear (e.g. high-risk pregnancies) that were not assessed in this investigation. However, the level of fear in women in care of an obstetrician is similar to fear levels in non-U.S. women and suggests consistency of fear levels among pregnant women in developed countries. Serious fear was not exclusive to obstetrical care and it is notable that there were women with high levels of fear who chose the care of a midwife, indicating that management of high levels of childbirth fear is a salient issue for all prenatal care providers. Greater fear of childbirth was associated with increased preference for maternal request $\mathrm{c}$-section, and four women indicated having already requested an elective c-section for fear. While this is a seemingly small number of women, it is $4.4 \%$ of the sample, and if applied to the 4 million women delivering annually in the U.S. [44] these findings suggest 176,000 women may be distressed enough to prefer surgery over vaginal delivery and to make this request of their providers. In addition to the increased expense for surgical delivery [45] there are ethical and medical concerns regarding maternal request c-section (e.g. increased mortality and complications in future pregnancies [46-48] or increased risk of respiratory difficulties in newborns [17]). There is also variability in terms of women's access to this option and physicians' willingness to provide elective c-section $[49,15]$ as well as limited evidence that maternal request $\mathrm{c}$-section prevents negative birth experience. $[50,51]$

While fear was higher among women without birth experience and women with prior difficult birth, these levels were still within the typical range of childbirth fear. Only among women with history of repeated sexual victimization and those struggling with depression and trauma symptomology (not mutually exclusive categories) did fear levels begin to show significant elevations. There is prior evidence for a relationship between anxiety and depression and fear of childbirth $[8,26]$, and sexual assault and fear of childbirth [1]; the current work suggests that depression mediates the relationship between these negative personal experiences and childbearing fear. Negative expectations and fear regarding childbirth may be rooted in belief systems associated with depression (e.g. global and stable negative beliefs regarding the world, self, and others) though this speculation requires additional study. The implication is that women with serious fear are not simply exaggerating typical concerns regarding childbirth, and that they are unlikely to be re-assured by minimizing these concerns (e.g. by presenting evidence regarding the very small number of catastrophic outcomes). Rather these women likely have substantive negative expectations that have been reinforced by difficult life experiences that reach far beyond the infrequent occurrence of birth. These results underscore the importance of identifying and treating depression in pregnant women and point to potential additional options for obstetrical providers attending patients with serious fear (i.e. psychotherapy in addition to or in place of either elective surgery or no treatment). On a practical level, this study shows that the 10-item EPDS can successfully identify women at an $82 \%$ increased risk for serious childbirth fear who could potentially benefit from psychological intervention and possibly reduce costly healthcare utilization.

One of the primary contributions of this work is that the incidence of childbearing fear in American women is similar to the incidence of 
serious fear found in non-U.S. women, and suggests consistency in fear rates across women from various developed countries. While this study provides greater understanding of the relationship of psychopathology to childbearing fear in primarily Caucasian, college-educated women, its generalizability may be limited, and it is unknown whether this relationship would differ for women of other ethnicities, economic levels, or age (e.g. in pregnant adolescents). Investigations are also needed to determine the effect that greater levels of childbearing fear play in the provision of care for pregnant women in the U.S. (i.e. increased healthcare utilization, increased provider burden), as well as to better understand the relationship between excessive fear, depression, and maternal request c-section.

\section{Contributions}

Jennifer Runnals: topic development, data collection, analysis, manuscript preparation, writing. Scott Vrana: topic development, analysis, writing, editorial assistance.

\section{Competing interests}

The authors have no competing interests to report.

\section{References}

1. Heimstad R, Dahloe R, Laache I, Skogvoll E, Schei B (2006) Fear of childbirth and history of abuse: implications for pregnancy and delivery. Acta Obstetricia et Gynecologica Scandinavica 85: 435-440. [Crossref]

2. Johnson R, Slade P (2002) Does fear of childbirth during pregnancy predict emergency caesarean section? BJOG: Int J Obstet Gynaecol 109: 1213-1221. [Crossref]

3. Nieminen K, Stephansson O, Ryding EL (2009) Women's fear of childbirth and preference for cesarean section--a cross-sectional study at various stages of pregnancy in Sweden. Acta Obstet Gynecol Scandinavica, 88: 807-813. [Crossref]

4. Rouhe H, Salmela-Aro K, Halmesmäki E, Saisto T (2009) Fear of childbirth according to parity, gestational age, and obstetric history. BJOG 116: 67-73. [Crossref]

5. Ryding EL, Wijma B, Wijma K, Rydhstrom H (1998) Fear of childbirth during pregnancy may increase the risk of emergency cesarean section. Acta Obstet Gynecol Scandinavica 77: 542-547. [Crossref]

6. Söderquist J, Wijma K, Wijma B (2004) Traumatic stress in late pregnancy. J Anxiety Disord 18: 127-142. [Crossref]

7. Zar M, Wijma K, Wijma B (2002) Relations between anxiety disorders and fear of childbirth during late pregnancy. Clin Psychol Psychother 9: 122-130. [Crossref]

8. Andersson L, Sundstrom-Poromaa I, Wulff M, Astrom M, Bixo M (2004) Implications of antenatal depression and anxiety for obstetric outcome. Obstet. Gynecol 104: 467476. [Crossref]

9. Poggi L, Goutaudier N, Séjourné N, Chabrol H (2018) When Fear of Childbirth is Pathological: The Fear Continuum. Matern Child Health J 22: 772-778. [Crossref]

10. Reck, C, Zimmer, K, Dubber, S, Zipser, B, Schlehe, B, et al. (2013) The influence of general anxiety and childbirth-specific anxiety on birth outcome. Arch Women Ment Hlth, 16: 363-369. [Crossref]

11. Dunkel-Schetter C (1998) Maternal stress and preterm delivery. Prenat Neonat Med 3:3942.

12. Stoll K, Edmonds JK, Hall WA (2015) Fear of childbirth and preference for Cesarean delivery among young American women before childbirth: A survey study. Birth 42: 270-276. [Crossref]

13. Hamama-Raz, Y, Sommerfeld, E, Ken-Dror, D, Lacher, R, Ben-Ezra, M (2017) The role of intra-personal and interpersonal factors in fear of childbirth: A preliminary study. Psychiatr Quart 88: 385-396. [Crossref]

14. Hildingsson I, Rådestad I, Rubertsson C, Waldenström U (2002) Few women wish to be delivered by caesarean section. BJOG 109: 618-623. [Crossref]

15. Saisto TE, Ylikorkala OL, Halmesmaki E (1999) Factors associated with fear of delivery in second pregnancies. Obstet Gynecol 94: 679-682. [Crossref]

16. Habiba M, Kaminski M, Da FM, Marsal K, Bleker O, et al. (2006) Caesarean section on request: a comparison of obstetricians' attitudes in eight European countries. BJOG: Int J Obstet Gynaecol 113: 647-656. [Crossref]
17. McFarlin BL (2004) Elective cesarean birth: issues and ethics of an informed decision. J Midwifery Wom Heal 49: 421-429. [Crossref]

18. Areskog B, Kjessler B, Uddenberg N (1982) Identification of women with significan fear of childbirth during late pregnancy. Gynecol Obstet Invest 13: 98-107. [Crossref]

19. Melender HL, Lauri S (1999) Fears associated with pregnancy and childbirth -experiences of women who have recently given birth. Midwifery 15: 177-182. [Crossref]

20. Sheen, K, Slade, P (2018) Examining the content and moderators of women's fears for giving birth: A meta-synthesis. J Clin Nurs. [Crossref]

21. Hofberg K, Ward MR (2004) Fear of childbirth, tocophobia, and mental health in mothers: the obstetric-psychiatric interface. Clin Psychol Psychother 47: 527-534. [Crossref]

22. Alehagen S, Wijma K, Wijma B (2001) Fear during labor. Acta Obstet Gynecol Scand 80: 315-320. [Crossref]

23. Wijma K (2003) Why focus on 'fear of childbirth'? J Psychosom Obstet Gynaecol 24: 141-143. [Crossref]

24. Zar M, Wijma K, Wijma B (2001) Pre- and postpartum fear of childbirth in nulliparous and parous women. Scandinavian J Beh Therapy 30: 75-84.

25. Wijma K, Wijma B, Zar M (1998) Psychometric aspects of the W-DEQ; a new questionnaire for the measurement of fear of childbirth. J Psychosom Obstet Gynaecol 19: 84-97. [Crossref]

26. Klabbers, GA, van Bakel, HJA, van den Heuvel, MMA, Vingerhoets, AJJM 2016. Severe fear of childbirth: Its features, assesment, prevalence, determinants, consequences and possible treatments. Psihologijske Teme 25: 107-127.

27. Cox JL, Holden JM, Sagovsky R (1987) Detection of postnatal depression: Developmen of the 10-item Edinburgh Postnatal Depression Scale. Brit J Psychiat 150: 782-786.

28. Wickberg B, Tjus T, Hwang P (2005) Using the EPDS in routine antenatal care in Sweden: A naturalistic study. J Reprod Infant Psychol 23: 33-41.

29. Lyons S (1998) A prospective study of post traumatic stress symptoms 1 month following childbirth in a group of 42 first-time mothers. J Reprod Infant Psychol 16 : 91-105.

30. Murray D, Cox J (1990) Screening for depression during pregnancy with the Edinburgh Depression Scale (EPDS). J Reprod Infant Psychol 33: 543-562.

31. Foa EB, Cashman L, Jaycox L, Perry K (1997) The validation of a self-report measure of posttraumatic stress disorder: The Posttraumatic Diagnostic Scale. Psychol Assess 9: 445451 .

32. Ayers S, Pickering AD (2001) Do women get posttraumatic stress disorder as a result of childbirth? A prospective study of incidence. Birth 28: 111-118. [Crossref]

33. Creedy DK, Shochet IM, Horsfall J (2000) Childbirth and the development of acute trauma symptoms: Incidence and contributing factors. Birth 27: 104-111. [Crossref]

34. Ayers S, Joseph S, Kenzie-McHarg K, Slade P, Wijma K (2008) Post-traumatic stress disorder following childbirth: current issues and recommendations for future research. J Psychosom Obstet Gynaecol 29: 240-250. [Crossref]

35. Breslau N, Davis G, Andreski P, Peterson E (1991) Traumatic events and posttraumatic stress disorder in an urban population of young adults. Arch Gen Psychiat 48: 216-222. [Crossref]

36. Kessler RC, Sonnega A, Bromet E, Hughes M (1995) Posttraumatic stress disorder in the National Comorbidity Survey. Arch Gen Psychiat 52: 1048-1060.

37. Resnick HS, Kilpatrick DG, Dansky BS, Saunders BE (1993) Prevalence of civilian trauma and posttraumatic stress disorder in a representative national sample of women. J Consult Clinical Psychol 61: 984-991. [Crossref]

38. Saisto T, Salmela-Aro K, Nurmi JE, Halmesmäki E (2001) Psychosocial predictors of disappointment with delivery and puerperal depression. A longitudinal study. Acta Obstet Gynecol Scand 80: 39-45. [Crossref]

39. Cloitre M, Koenen K, Gratz K, Jakupcak M (2002) Differential diagnosis of PTSD in women. In: Kimerling R, Ouimette P, Wolfe, J, editors. Gender and PTSD. New York: The Guilford Press; p. 117-149.

40. Kimerling R, Alvarez J, Pavao J, Kaminski A, Baumrind N (2007) Epidemiology and consequences of women's revictimization. Womens Health Issues 17: 101-106. [Crossref]

41. Messman-Moore TL, Long PJ, Siegfried NJ (2000) The revictimization of child sexual abuse survivors: an examination of the adjustment of college women with child sexual abuse, adult sexual assault, and adult physical abuse. Child Maltreat 5: 18-27. [Crossref] 
42. Najdowski CJ, Ullman SE (2009) Prospective effects of sexual victimization on PTSD and problem drinking. Addict Behav 34: 965-968. [Crossref]

43. Norris R, Foster J, Weisshaar D (2002) The epidemiology of sex differences in PTSD across developmental, societal, and research contexts. In: Kimerling R, Ouimette P, Wolfe, J, editors. Gender and PTSD. New York: The Guilford Press; p. 3-42.

44. MacDorman MF, Declercq E, Menacker F, Malloy MH (2008) Neonatal mortality for primary cesarean and vaginal births to low-risk women: application of an "intention-totreat" model. Birth 35: 3-8. [Crossref]

45. Petrou S, Glazener C (2002) The economic costs of alternative modes of delivery during the first two months post-partum. Brit J Obstet Gynecol 109: 214-217. [Crossref]

46. Hemminki E, Merilainen J (1996) Long-term effects of cesarean sections: ectopic pregnancies and placental problems. Am J Obstet Gynecol 174: 1569-1574. [Crossref]
47. Schuitemaker N, van Roosmalen J, Dekker G, van Dongen P, van Geijn J, et al. (1997) Maternal mortality after cesarean section in the Netherlands. Acta Obstet Gynecol Scandinavia 76 : 332-336.

48. Wax JR, Cartin A, Pinette MG, Blackstone J (2004) Patient choice cesarean: an evidence based review. Obstet Gynecol Surv 59: 601-616. [Crossref]

49. Kwee A, Cohlen BJ, Kanhai HH, Bruinse HW, Visser GH (2004) Caesarean section on request: a survey in The Netherlands. Eur J Obset Gynecol Reprod Biol 113: 186190. [Crossref]

50. Waldenstrom U, Hildingsson I, Rubertsson C, Radestad I (2004) A negative birth experience: prevalence and risk factors in a national sample. Birth 31: 17-27. [Crossref]

51. Wiklund I, Edman G, Ryding EL, Andolf E (2008) Expectation and experiences of childbirth in primiparae with caesarean section. BJOG 115: 324-331. [Crossref]

Copyright: $\odot 2018$ Runnals JJ. This is an open-access article distributed under the terms of the Creative Commons Attribution License, which permits unrestricted use, distribution, and reproduction in any medium, provided the original author and source are credited. 